Original Contribution

\title{
AWARENESS AND PARTICIPATION OF OUTPATIENT DEPARTMENT PATIENTS WITH CHRONIC PAIN IN THE TREATMENT
}

\author{
R. Goranova-Spasova*
}

\author{
Faculty of Public Health, Medical University-Sofia, Sofia, Bulgaria
}

\begin{abstract}
Chronic pain as a condition is more and more common due to population ageing and the high prevalence of chronic non-communicable diseases. It has been demonstrated that pain affects all health-related dimensions of quality of life and analyses show that chronic pain is associated with high health costs.

PURPOSE: The aim of this study is to investigate the awareness and participation of patients with chronic pain in the treatment

METHODS: For the purposes of the study, a questionnaire was developed for a direct individual survey. Descriptive and analytical statistical methods were also used.

RESULTS: A total of 280 patients with different diagnoses who visited their physician with complaints of persistent pain were included in the study. Although the patients surveyed confirmed that they seek information about their therapy and are satisfied with the information they receive, a significant proportion of them do not think that they can always cope with chronic pain.

CONCLUSION: Good awareness of patients is of key importance for their participation in the treatment. Easily available, true and relevant information is a prerequisite for understanding the pain control options.
\end{abstract}

Key words: chronic pain, outpatient autonomy, patient compliance, partnership.

\section{INTRODUCTION}

Chronic pain as a condition is more and more common due to population ageing and the high prevalence of chronic non-communicable diseases. In developed countries, this pathology tends to develop in younger people. (1- 3)

Most authors define chronic pain as pain continuing 3 or 6 months since onset. (4) A popular alternative definition that involves no arbitrarily fixed duration is "pain that extends beyond the expected period of healing". (5) A systematic review of the literature from 2003 shows that between $10.1 \%$ and $55.2 \%$ of people in different countries suffer from chronic pain. (6) According to data from 2016 nearly 50 million Americans suffer from chronic pain and 19.6 million from highimpact chronic pain. (7) Chronic pain can be difficult to deal with. Depending on the nature of the pain (nociceptive or neuropathic), non-

Correspondence to: Radka Nikolaeva GoranovaSpasova, 8 Byalo more str., 1527 Sofia, Bulgaria, +359898240976, e-mail: r.goranova@foz.musofia.bg opioid and opioid medications, as well as alternative techniques for pain relief, are used. Patients with chronic pain also suffer from depression, anxiety, and sleep disturbances. Physicians prescribe antidepressants for treating the pain because of the relationship between chronic pain and depression. (7) Restraining physical activity due to a fear of the pain worsening results in weight gain, with all the associated health risks. It has been demonstrated that pain affects all healthrelated dimensions of quality of life. (8-10)

Analyses show that chronic pain is associated with high health-related costs. Patients with chronic pain receive more medical help, but they also report more dissatisfaction with the quality of medical services, including medical care. One of the reasons for dissatisfaction is the high expectations of such patients regarding both the therapy and the commitment of the healthcare professionals to solving their problem. (11)

The above considerations give us reason to view chronic pain as a public health problem which places a great burden on individuals, their families and the society as a whole. 
Pain management is a difficult process due to the subjective nature of pain. Patient's participation is essential for adequate diagnostic and treatment. Effective communication between the healthcare team (physician, nurse, physical therapist, and other healthcare and non-healthcare professionals) and the patient is necessary to promote pain self-management and achieve functional results of treatment. (9) Self-management includes skills and behavior which helps to improve the quality of life despite the presence of a chronic condition. Self-management is not a substitute for physical therapies, medications, and psychological support, but it is important for the increased self-esteem of patients. (3)

\section{PURPOSE OF THE STUDY}

The aim of this study is to investigate the awareness and participation of OPD (outpatient departments) patients with chronic pain in the treatment.

\section{MATERIALS AND METHODS}

The presented results are part of a larger study conducted in the North-Western region of the
GORANOVA- SPASOVA R.

Republic of Bulgaria. The object of observation, the logical and technical units and the associated signs were determined based on the objectives of the study.

This research included patients with chronic pain who visited their physician (general practitioner or specialist) between February 2019 and May 2019. The sample doesn't include hospitalized patients, and patients with terminal conditions.

The technical items were practices for general and specialized medical care on the territory of Vidin, Lom and Montana.

For the purposes of the study, a questionnaire was developed for a direct individual survey, examining several factors - demographic characteristics of the surveyed persons; use of medical resources; preferred methods of therapy; patient's awareness of treatment, side effects and adverse drug reactions; readiness for pain self-management.

Table 1. Demographic characteristics of the respondents

\begin{tabular}{ll}
\hline & $\mathrm{N}=280$ \\
\hline Age & \\
\hline$<40$ years & $15,1 \%$ \\
$41-60$ years & $56,8 \%$ \\
$60+$ years & $28,1 \%$ \\
\hline Gender & $39,3 \%$ \\
\hline Male & $60,7 \%$ \\
Female & \\
\hline Living area & $72,9 \%$ \\
\hline City & $27,1 \%$ \\
\hline Village & \\
\hline Marital status & $63,6 \%$ \\
\hline Married & $12,1 \%-$ \\
Unmarried & $10,7 \%$ \\
Divorced & $13,6 \%$ \\
Widow & \\
\hline Education level & $7,2 \%$ \\
\hline Primary or lower & $56,8 \%$ \\
Secondary & $15,1 \%$ \\
Semi- high & $20,9 \%$ \\
High & \\
\hline Employment & $49,3 \%$ \\
\hline Employed & $6,4 \%$ \\
Unemployed & $40 \%$ \\
Retired & $4,3 \%$ \\
Retired due to illness &
\end{tabular}


A wide range of statistical methods were used to process the data obtained:

1. Descriptive statistics (mean, absolute and relative frequencies);

2. Chi-square test or Fisher's exact test when examining dependencies between descriptive (categorical) data with two or more categories;

3. Graphic analysis - to present the results.

The critical level of significance used was $\alpha=$ 0.05 . The specialized statistical package SPSS (Statistical Package for Social Sciences), version 13.0, was used to process the study data.

\section{RESULTS AND DISCUSSION ACTIVITIES TO CONTROL THE OBESITY}

GORANOVA-SPASOVA R.

A total of 280 patients with different diagnoses who visited their physician with complaints of persistent pain were included in the study. (Table 1)

To achieve our objective, we investigated the respondents' demand for medical services. We asked the patients how often they visited their physician and whether they were subject to periodical monitoring in relation to their disease. More than half of the respondents $(58.7 \%)$ stated that they visited their physician three times (or more) per year, which shows significant reliance on medical services. 29\% responded that they visited their physician twice a year, and only $8.7 \%$ - once a year. (Figure 1)

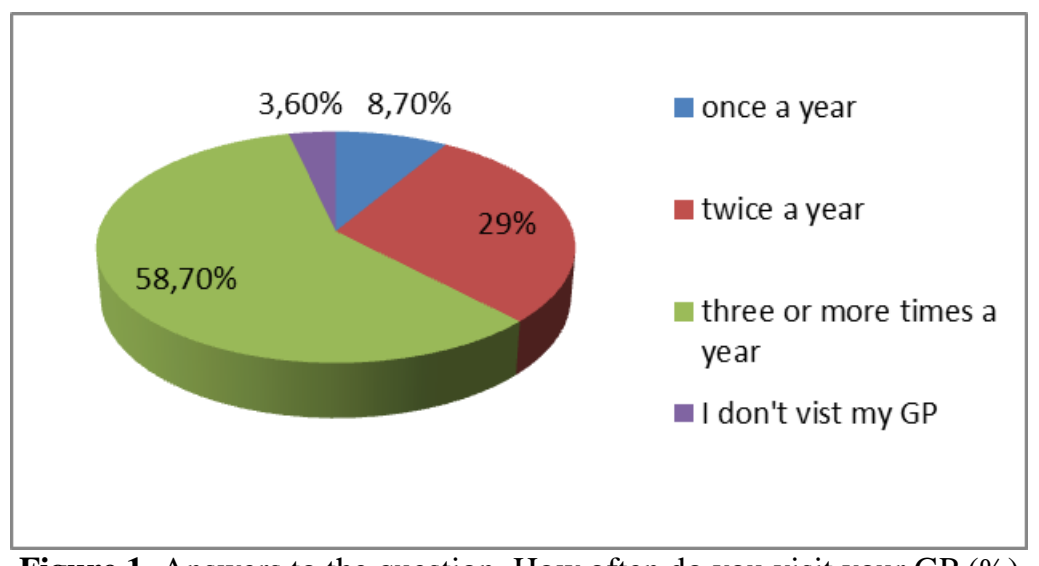

In our sample, $32.6 \%$ were subject to periodical monitoring in relation to their chronic condition. The pain most commonly reported by the respondents was pain in the joints, and it was of inflammatory or degenerative nature (coxarthrosis, gonarthrosis, arthritis, etc.). A substantial proportion of the respondents suffered from migraine or other types of headache.

\section{METHODS FOR PAIN TREATMENT}

In regard to pain treatment, the largest proportion of individuals (59.5\%) answered that they were using prescription medicines, other $41.2 \%$ - over-the-counter medications, $32.1 \%$ - physical therapy, $12.2 \%$ - alternative medicine, and only $6.9 \%$ - opioid medications and $3.8 \%$ - antidepressants. In contrast to the global opioid crisis, we found that a very low number of Bulgarian patients were treated with opioid analgesics. (Figure 2)

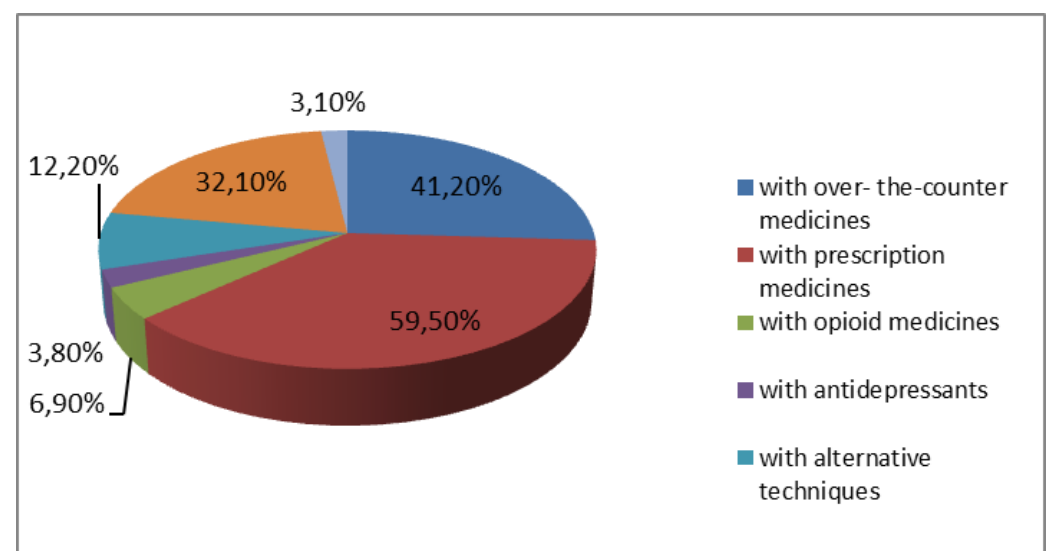

Figure 2. Answers to the question "If you suffer from chronic pain, how do you deal with it (\%) 


\section{AWARENESS OF TREATMENT}

Patient awareness of the use, side effects and drug interactions is essential for the selfmanagement of pain and its effective control. For this reason, we examined the respondents' opinions and the relationship between respondents' demographic characteristics (sex, age, marital status, education and employment) and their desire to be informed and involved in the treatment. Patients studied were aware of the expected effects of the drugs and the manner of administration of the medicines but they lacked information regarding the side effects.

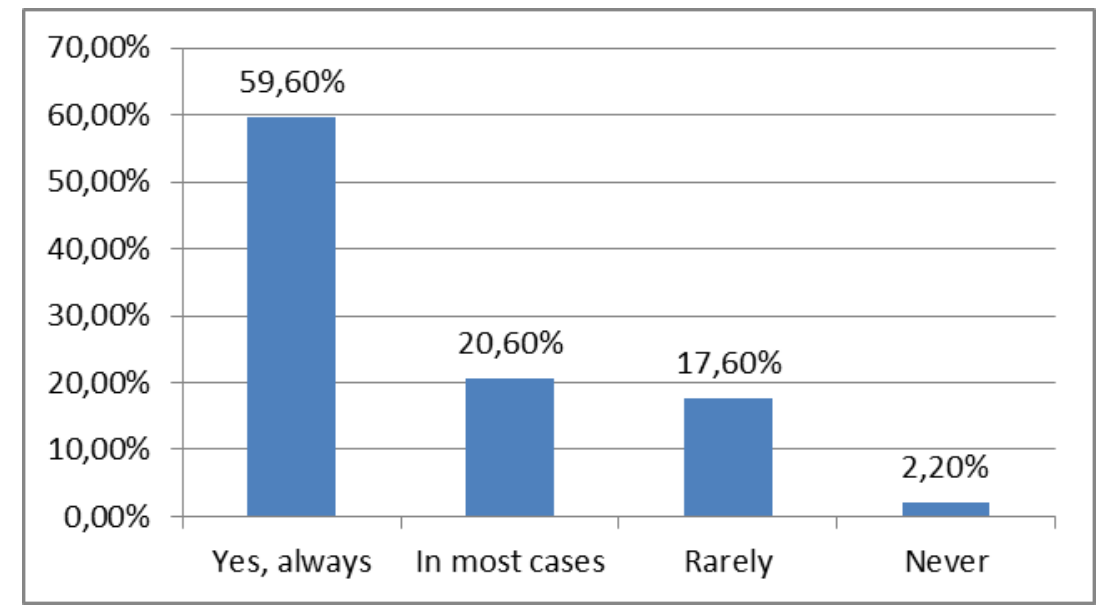

Figure 3. Answers to the question "Do you know beforehand how to take the pain medication" (\%)

It is noteworthy that great proportion of patients with secondary and semi-higher education seeks information about the medication; while the highest percentage of participants with higher education answered that they never seek information in advance.

Patients with semi-higher and higher education are more likely to seek information about the
It is noteworthy that more than half of the patients seek information about the use of analgesics in advance. However, the proportion of participants who answered "rarely" was not insignificant (17.6\%) and $2.2 \%$ answered "never". (Figure 3) A significant proportion of married patients (69\%) seek information on how to take pain medications in advance. Unmarried respondents were most likely to answer „rarely" and the difference in the answers to this question between the marital status groups is statistically significant.

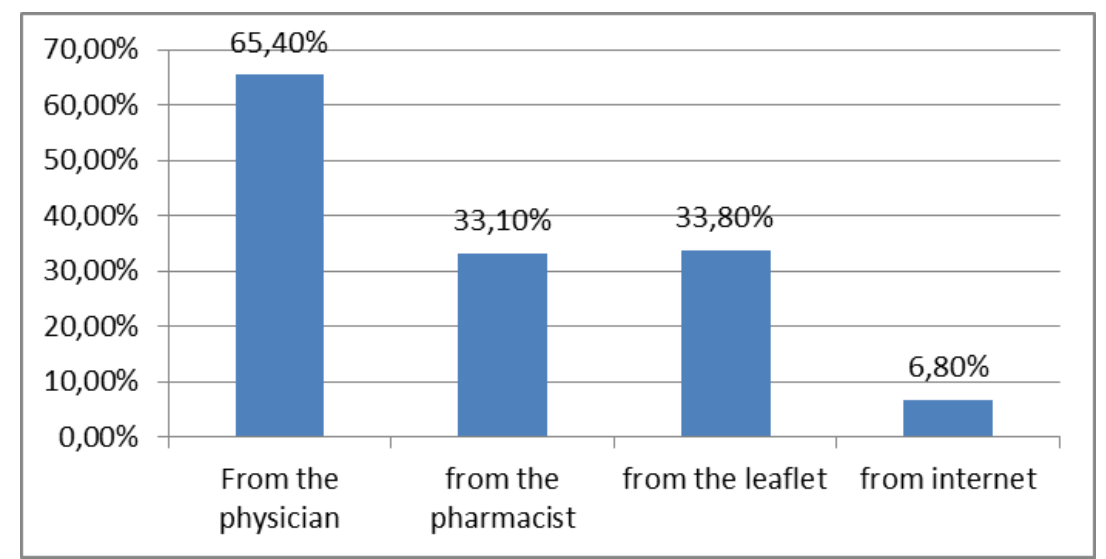

Figure 4. Answers to the question "From where do you get information about pain medicine intake"

The quality of the information received and its comprehensibility for the patient is essential for patient awareness. Figure 5 shows the medication on the Internet compared to the other groups, and there is a statistically significant difference in answers to this question. $65.4 \%$ ask their physician for information, $33.1 \%$ - their pharmacist, and $33.8 \%$ find information in the drug product insert. (Figure 4) distribution of participants according to the answer to the question "Was the information you received clear and understandable for 
GORANOVA- SPASOVA R.

you?". The information was nonunderstandable for a minor percentage of respondents, while the proportion of male patients is a little higher. No statistically significant relationship between age, marital status, education and employment in the answers to this question was found in our sample.

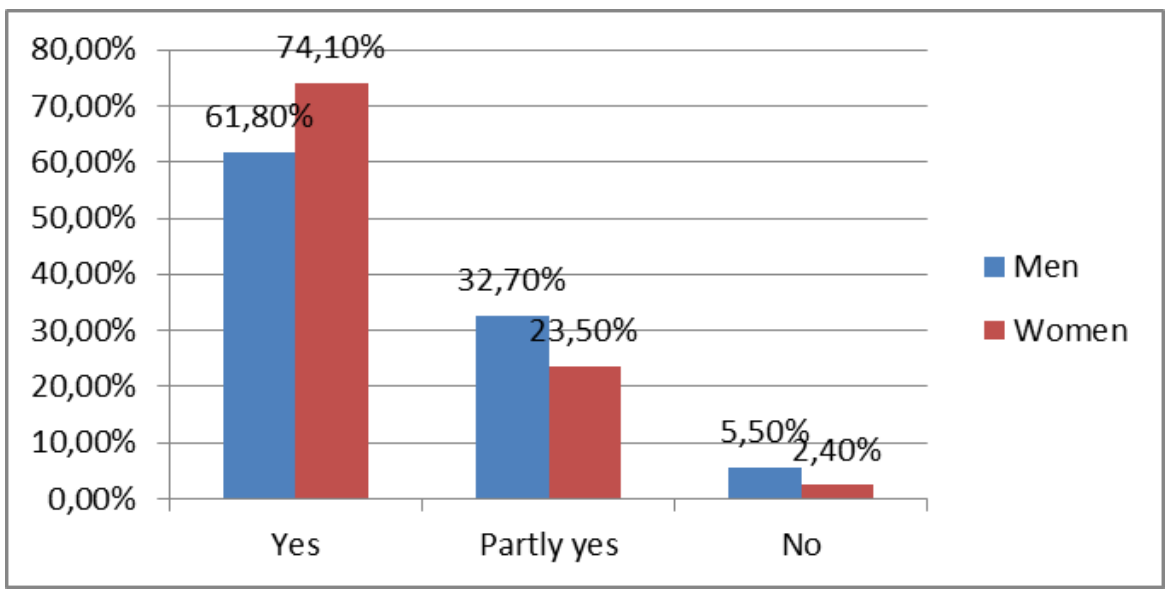

Figure 5. Answers to the question "Was the information you received clear and understandable for you"

Most patients, particularly the elderly, suffer from multiple diseases (polymorbidity) which requires the use of various medications with various side effects and adverse drug reactions. Figures 6 and 7 show the distribution of participants based on their awareness of adverse drug reactions and drug interactions at the start of the therapy. No statistically significant difference in respondents' answers to these questions was found in terms of sex, marital status, education and employment.

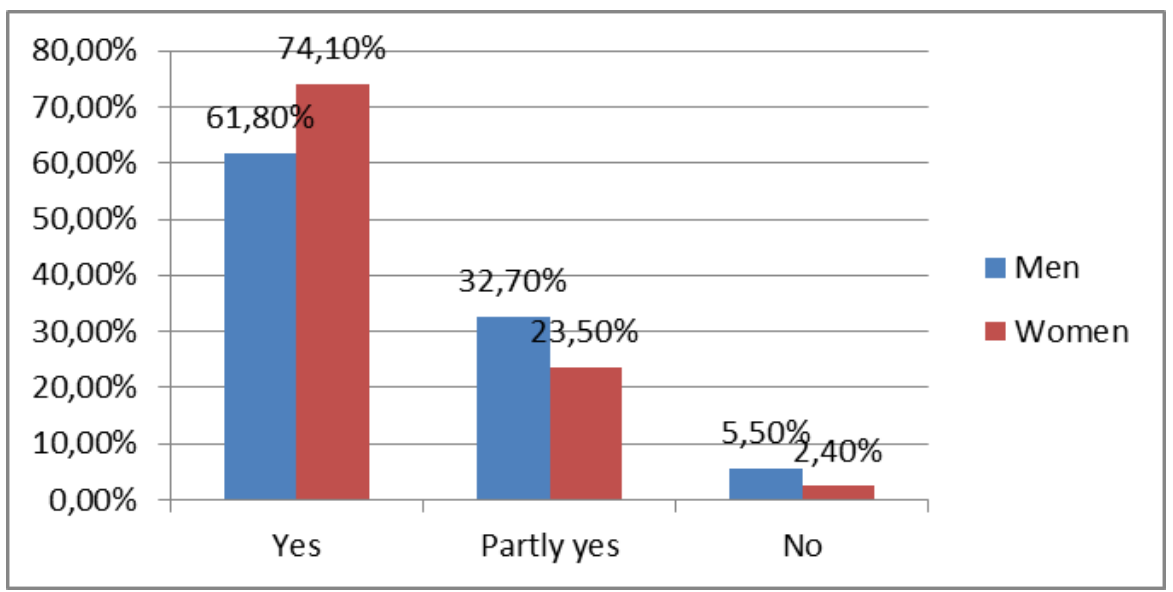

Figure 6. Answers to the question "Are you informed in advance of the side effects of the medicine you are taking"

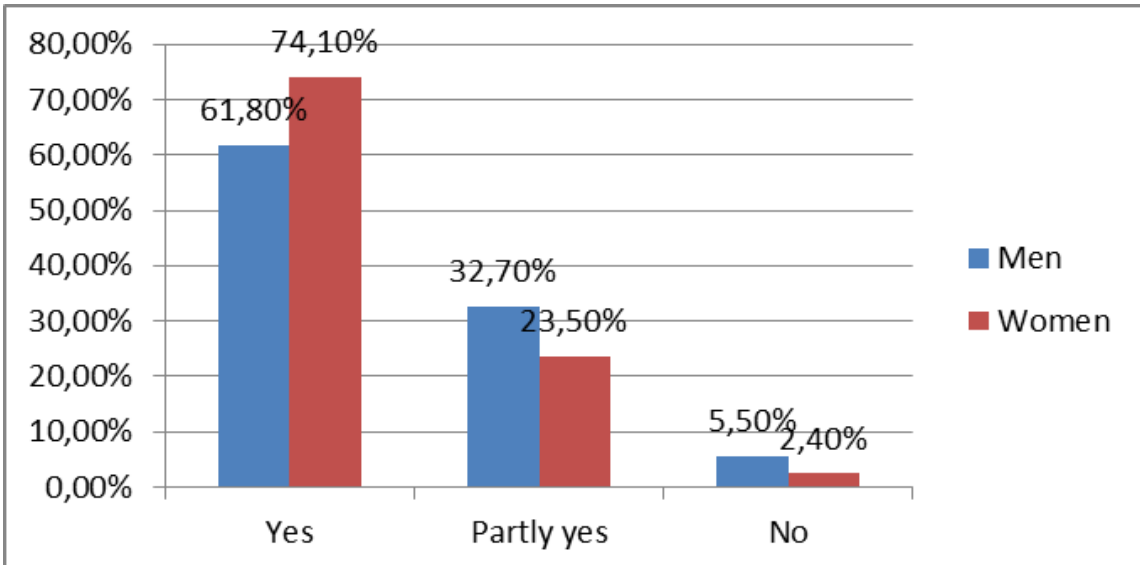

Figure 7. Answers to the question „Are you aware of adverse drug reactions if you are taking other medicines" 
GORANOVA- SPASOVA R.

\section{SELF-MANAGEMENT OF PAIN}

The answers to the question regarding the selfmanagement of chronic pain are not encouraging. Only $10 \%$ of the respondents answered that they can always cope with pain by themselves, $30.7 \%$ answered with "rather yes", 43.6\% answered with "rather no" and $10 \%$ could not answer to this question. Figure 8 shows the distribution of answers to this question according to the sex of the respondents.

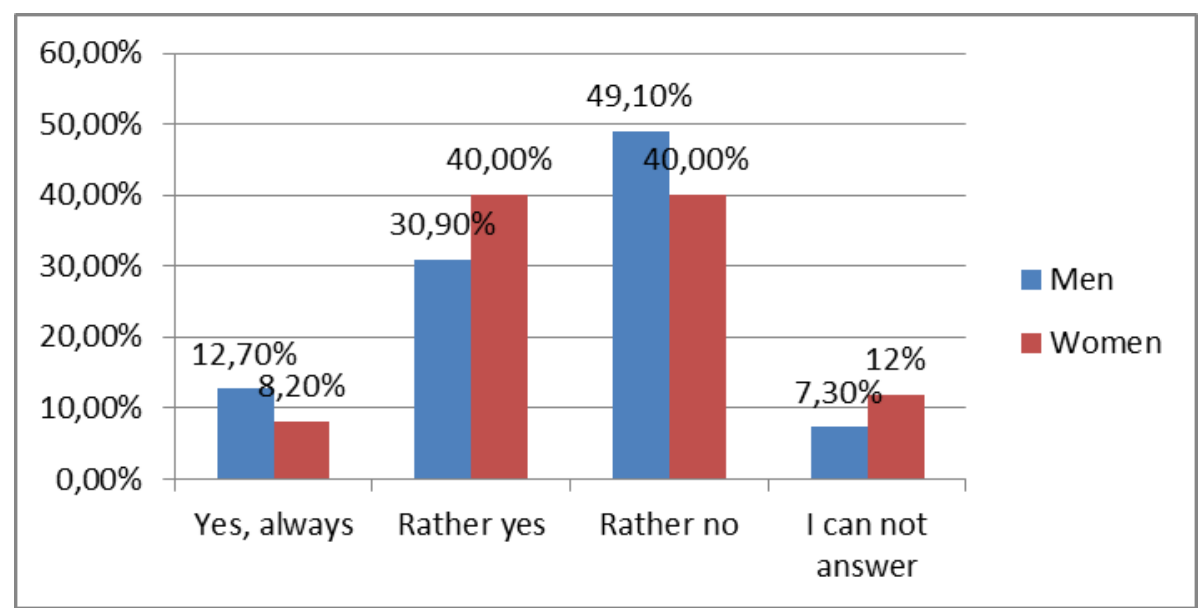

Figure 8. Answers to the question "Do you think you can manage the pain by yourself"

\section{DISCUSSION}

Today's leading model of a "doctor-patient" relationship is the Model of Autonomy. One of the key traits of this model is the person as a moral subject. It is based on the ethical principle of autonomy - respecting the right of self-determination of the autonomous person (12-13). Some features of the autonomous model include:

- The patient receives complete and accurate information about his/her condition, all test results, the complete and accurate diagnosis, the treatment options and the prognosis, as well as information about what will happen if he/she refuses treatment.

- It is the patient's right to determine what is good for him/her.

- The patient is responsible for his/her decision;

- The patient gives an informed consent. (14)

The most important factor in managing chronic illness and chronic pain is the role of the patient. Self-management is the best way to improve patient's level of activity and reduce disability. (15)

When people take control of their chronic condition, they feel empowered to resume normal activities and participate in social life. Singh et al. (2013) studied 264 patients and found that though a considerable number of patients were aware about the therapeutic effects of the drugs and the manner of administration of the medicines; they lacked information regarding the side effects, warnings and the information their doctor may require at the next consultation. (16)

Rubio et al. (2015) in their study found that patients with chronic pain were least aware of "drug safety" $(1.9 \%)$ and the highest lack of correct information was with respect to the "safety" of the medication. (17)

Breivik et al. (2013) made systematic review of the literature and discussed that the provision of pain education for patients varies internationally. (18) Some studies show that patient's education is helpful to improve functioning, well-being and therapy adherence in patients with chronic pain (15)

Gjesdal et al. (2018) emphasize the importance of a holistic understanding of and support for more person-centered practice to answer patients' expectations and pain management needs. (19)

Worldwide, patients' involvement in the control of chronic pain is discussed mainly in the setting of administration of opioid analgesics, which are known to have an excellent analgesic effect in both acute pain and pain in terminal conditions, but also in persistent pain. Our data shows that opioid medications are rarely prescribed for pain 
relief in the outpatient medical care in Bulgaria.

\section{CONCLUSION}

Our results demonstrate that most patients rely on the conventional medicine for treating their chronic pain. A very small portion relies on natural products and alternative medicine options. The analgesics used are mainly oral and prescription or over-the-counter. Although the patients surveyed confirmed that they seek information about their therapy and are satisfied with the information they receive, a significant portion of them do not think that they can always cope with chronic pain.

Good awareness of patients is of outmost importance for their participation in the treatment. Readily available, true and relevant information is a prerequisite for understanding the pain control options as it gives confidence to patients suffering from a chronic disease.

Unfortunately, a significant portion of participants did not feel that they can selfmanage their pain, which is a factor for the poor quality of life. Further discussion on treatment options and home pain management options with the physician would contribute to autonomy and would increase patients' satisfaction with medical services.

\section{REFERENCES}

1. National Statistics Institute $<$ http://www.nsi.bg/bg/content/3280/здравео пазване>

2. National Centre of Public Health and Analyses

<http://ncphp.government.bg/index.php?optio $\mathrm{n}=\mathrm{com} \_$content $\&$ view $=$ category\&layout $=$ blo g\&id=96\&Itemid $=640 \&$ lang $=$ bg $>$

3. Vodenicharov, Ts., Popova, S., Mutafova, M. et al. Social medicine, GoreksPress, Sofia 2013.

4. International Association for the Study of Pain: Pain Definitions. Derived from The need of taxonomy. Pain, 6 (3): 247-8, 1979.

5. Turk, D., Okifuji, A., Pain terms and taxonomies. In: Loeser, D., Butler, S., Chapman, J. et al. (eds.). Bonica's Management of Pain (3rd ed.). Lippincott Williams \& Wilkins., pp18-25, 2001.

6. Harstall C., Ospina M., How Prevalent Is Chronic Pain? Pain Clinical Updates, International Association for the Study of Pain, 11 (2): 1-4, 2003.

7. Dahlhamer J., Lucas J., Zelaya, C., et al. Prevalence of Chronic Pain and High-Impact Chronic Pain Among Adults - United States,
GORANOVA- SPASOVA R. 2016, MMWR Morb Mortal Wkly Rep, 67: 1001-1006, 2018.

8. Shtereva- Nikolova N., Goranova-Spasova, R., Ethics and Quality of Life. In: Manual of Medical Ethics, ID Prifnt (Ed.), Sofia pp 8493, 2014.

9. McCarberg B., Nicholson B., Todd K., et al. The impact of pain on quality of life and the unmet needs of pain management: results from pain sufferers and physicians participating in an Internet survey, Am J Ther, 15 (4): 312-20, 2008.

10. Cousins M., Brennan F., Carr D., Pain relief: a universal human right, Pain. 112 (1-2): 1-4, 2004.

11. Verbeek J., Sengers M., Riemens L., et al. Patient expectations of treatment for back pain: a systematic review of qualitative and quantitative studies. Spine, 29 (20): 23092318, 2004.

12. Beauchamp T., Childress J. Principles of Biomedical Ethics, 4th ed. Oxford University Press (Ed.), Oxford, 1994.

13. Shtereva- Nikolova N., Informed consentessence, meaning and application in outpatient practice, RA Euromedia, Sofia, 2015.

14. Shtereva- Nikolova N., Goranova-Spasova, R., Models of relationships. In: Manual of Medical Ethics, Sofia, ID Prifnt (Ed.), Sofia, pp 14-23, 2014.

15. Oldenmenger W., Sillevis Smitt P., van Montfort C., et al. A combined pain consultation and pain education program decreases average and current pain and decreases interference in daily life by pain in oncology outpatients: a randomized controlled trial. Pain, 152: 2632-2639, 2011.

16. Singh J., Singh N., Kumar R., et al. Awareness about prescribed drugs among patients attending Out-patient departments, Int J Appl Basic Med Res, 3(1): 48-51, 2013.

17. Rubio J., García-Delgado P., Iglésias-Ferreira P., et al. Measurement of patients' knowledge of their medication in community pharmacies in Portugal. Cien Saude Colet, 20(1): 219-28, 2015.

18. Breivik H., Eisenberg E., O'Brien T., The individual and societal burden of chronic pain in Europe: the case for strategic prioritisation and action to improve knowledge and availability of appropriate care, BMC Public Health, 13: 1229, 2013.

19. Gjesdal K., Dysvik E., Furnes B., Living with chronic pain: Patients' experiences with healthcare services in Norway. Nurs Open, 5(4): 517-526, 2018. 